University of Nebraska - Lincoln

DigitalCommons@University of Nebraska - Lincoln

Faculty Publications: Department of

Entomology

Entomology, Department of

December 2003

\title{
Characterization of General Esterases from Methyl Parathion- Resistant and -Susceptible Populations of Western Corn Rootworm (Coleoptera: Chrysomelidae)
}

\author{
Xuguo Zhou \\ University of Nebraska-Lincoln \\ Michael E. Scharf \\ University of Nebraska-Lincoln \\ Lance J. Meinke \\ University of Nebraska-Lincoln, Imeinke1@unl.edu \\ Laurence D. Chandler \\ University of Nebraska-Lincoln \\ Blair D. Siegfried \\ University of Nebraska-Lincoln, bsiegfried1@ufl.edu
}

Follow this and additional works at: https://digitalcommons.unl.edu/entomologyfacpub

Part of the Entomology Commons

Zhou, Xuguo; Scharf, Michael E.; Meinke, Lance J.; Chandler, Laurence D.; and Siegfried, Blair D., "Characterization of General Esterases from Methyl Parathion-Resistant and -Susceptible Populations of Western Corn Rootworm (Coleoptera: Chrysomelidae)" (2003). Faculty Publications: Department of Entomology. 40.

https://digitalcommons.unl.edu/entomologyfacpub/40

This Article is brought to you for free and open access by the Entomology, Department of at DigitalCommons@University of Nebraska - Lincoln. It has been accepted for inclusion in Faculty Publications: Department of Entomology by an authorized administrator of DigitalCommons@University of Nebraska - Lincoln. 


\section{Characterization of General Esterases from Methyl Parathion-Resistant and -Susceptible Populations of Western Corn Rootworm (Coleoptera: Chrysomelidae)}

Xuguo Zhou, Michael E. Scharf, Lance J. Meinke, Laurence D. Chandler, and Blair D. Siegfried

Journal of Economic Entomology

Volume 96, Issue 6 (December 2003) pp. 1855-1863

DOI: 10.1603/0022-0493(2003)096[1855:COGEFM]2.0.CO;2

Authors may post electronic reprints of their own journal articles after an embargo period of two years has passed from the date of publication. Also, authors must include on the electronic reprint the following statement:

This article is the copyright property of the Entomological Society of America and may not be used for any commercial or other private purpose without specific written permission of the Entomological Society of America. 


\title{
Characterization of General Esterases from Methyl Parathion-Resistant and -Susceptible Populations of Western Corn Rootworm (Coleoptera: Chrysomelidae)
}

\author{
XUGUO ZHOU, MICHAEL E. SCHARF, ${ }^{1}$ LANCE J. MEINKE, LAURENCE D. CHANDLER, ${ }^{2}$ \\ AND BLAIR D. SIEGFRIED ${ }^{3}$
}

Department of Entomology, University of Nebraska-Lincoln, NE 68583

\begin{abstract}
J. Econ. Entomol. 96(6): 1855-1863 (2003)
ABSTRACT A consistent correlation between elevated esterase activity and methyl parathion resistance among Nebraska western corn rootworm, Diabrotica virgifera virgifera LeConte, populations has previously been documented. Characterization of general esterase activity using naphtholic esters as model substrates indicated that differences between resistant and susceptible strains could be maximized by optimizing assay conditions. The optimal conditions identified here were similar to those reported for other insect species. The majority of general esterase activity was found in the cytosolic fractions of resistant populations, whereas the activity was more evenly distributed between cytosolic and mitochondrial/nuclear fractions in the susceptible population. General esterase activity was predominately located in the adult thorax and abdomen. Although there were significant differences in general esterase activities between resistant and susceptible populations, the differences exhibited in single beetle activity assays did not provide sufficient discrimination to identify resistant individuals. In contrast, single larva activity assays provided greater discrimination and could be considered as an alternative to traditional bioassay techniques.
\end{abstract}

KEY WORDS Diabrotica virgifera virgifera, esterase, insecticide resistance, methyl parathion, organophosphate

THE WESTERN CORN ROOTWORM, Diabrotica virgifera virgifera LeConte, is the most devastating insect pest of field corn, Zea mays L., in the Corn Belt (Levine and Oloumi-Sadeghi 1991). Root feeding by larvae causes both physiological and mechanical damage (Spike and Tollefson 1991). In contrast, adult rootworms cause only limited damage, although in some severe cases, silk feeding by adults reduces corn yield by adversely affecting pollination (Meinke 1995). Crop losses and management expenses attributed to Diabrotica species cost producers millions of dollars annually (Metcalf 1986, Pike et al. 1995).

Crop rotation, soil insecticide-based larval control, and foliar insecticide-based adult control have been the traditional rootworm management strategies for many years in Nebraska. Because of a readily accessible supply of water for irrigation, continuous corn production has often been the most economic option for corn producers in certain areas of Nebraska (Pike et al. 1995). The chlorinated hydrocarbons were the first synthetic insecticide class to be introduced in Nebraska for larval control in the late 1940s (Hill et al.

\footnotetext{
${ }^{1}$ Department of Entomology, Purdue University, West Lafayette, IN $47907-1158$.

${ }^{2}$ Red River Valley Experiment Station, USDA-ARS, Fargo, ND 58105 .

${ }_{3}^{3}$ E-mail: bsiegfried1@unl.edu.
}

1948). However, as a consequence of their broadcast application and extreme persistence, resistance to cyclodienes was detected in less than a decade (Ball and Weekman 1963, Metcalf 1986). In certain areas of the Platte Valley of south central Nebraska, adult rootworm control was adopted after the development of cyclodiene resistance (Meinke 1995). Microencapsulated methyl parathion (Penncap M) eventually became the most commonly used insecticide formulation. Because of its low cost and relatively long persistence, Penncap M was used consistently in some areas of the state for extended periods. Repeated applications of carbaryl followed by Penncap M in these areas led to control failures in the early 1990s (Meinke et al. 1997).

In vivo metabolism experiments with ${ }^{14} \mathrm{C}$-labeled ethyl parathion and synergism bioassays with the esterase inhibitor (S,S,S,-tributyl phosphoretrithiate) revealed involvement of an esterase-mediated resistance in rootworm populations from Phelps and York counties, Nebraska (Miota et al. 1998). Elevated esterase activities toward the model substrates $\alpha$ - and $\beta$-naphthyl acetate were exhibited in both larval and adult stages of Phelps and York county populations (Wright et al. 2000). A consistent correlation between elevated esterase activity as determined by native polyacrylamide gel electrophoresis and methyl para- 
thion resistance among Nebraska western corn rootworm populations has been documented previously (Zhou et al. 2002).

In Nebraska, uniform use of aerially applied contact insecticides over large geographic areas imitates the scale and magnitude of selection associated with areawide management (Comis 1997) and possibly that of transgenic coleopteran-targeted crops. Characterizing and monitoring existing esterase-mediated organophosphate resistance will provide useful information with regard to developing approaches that minimize the impact of these newer technologies on resistance development and proliferation. Therefore, the objectives of this research were to 1) optimize conditions for assay of $D$. $v$. virgifera esterase activity, 2) characterize differences in esterase activity between resistant and susceptible populations, and 3) evaluate the diagnostic potential of esterase activity assays with individual D. v. virgifera.

\section{Materials and Methods}

D. v. virgifera. Field populations of adult D. v. virgifera were collected from Nebraska during late July and August 1998 and represented areas previously identified as being resistant, susceptible, or intermediate based on survival at a diagnostic methyl parathion concentration (Zhou et al. 2002). Susceptible populations were collected from Saunders, Hall, and Buffalo counties, and resistant populations were collected from Phelps and York counties. Two additional populations from Phelps and Gosper counties represented populations with intermediate levels of resistance. All populations were collected before seasonal adult control measures had been initiated and were maintained in the laboratory at ambient temperature on a photoperiod of 14:10 (L:D) h and maintained on a standard diet of head lettuce, and sweet corn for 1-5 $\mathrm{d}$ before storage at $-80^{\circ} \mathrm{C}$ for later determination of esterase activity.

For all other experiments, field-collected Saunders, York, and Phelps county beetles (3,000-5,000 per site) were shipped to the USDA-ARS Northern Grain Insect Research Laboratory in Brookings, SD. Standard procedures were followed to collect and maintain eggs until termination of diapause and to establish subsequent generations (Jackson 1986). Lab-reared third instars were returned to the University of NebraskaLincoln for single insect esterase activity assays, and adults were used to optimize conditions for esterase activity measurement.

Rootworm eggs provided by USDA-ARS Northern Grain Insect Research Laboratory were used to assess esterase activity across developmental stages. D. $v$. virgifera egg cohorts were hatched at the same time in petri dishes, and neonates were fed on corn seedlings. Standard rearing techniques adapted from Jackson (1986) were used to maintain $D$. v. virgifera populations through all developmental stages. First and third instars were collected during the rearing process and stored immediately at $-80^{\circ} \mathrm{C}$ for subsequent esterase activity assays.
Chemicals. Naphtholic esters and biochemical reagents were purchased from Sigma (St. Louis, MO). Electrophoresis reagents were purchased from BioRad (Hercules, CA). Protein assay reagents and bovine serum albumin were purchased from Pierce Chemical (Rockford, IL). All other chemicals and solvents used were reagent grade or better.

Enzyme Preparation. Abdomens of 10 rootworm beetles were homogenized in $1.0 \mathrm{ml}$ of ice-cold homogenization buffer ( $0.1 \mathrm{M}$ sodium phosphate, $\mathrm{pH} 7.8$, $0.1 \%$ Triton $\mathrm{X}-100$ ) with a Teflon glass (Potter-Elvehjem) homogenizer. The homogenate was centrifuged in an Eppendorf microcentrifuge (Brinkmann Instruments, Westbury, NY) at $10,000 \times g$ and $4^{\circ} \mathrm{C}$ for $20 \mathrm{~min}$. The lipid layer was removed from the top of supernatant with an ice-cold metal spatula and by filtration through glass wool. The supernatant, diluted as necessary, was used as the enzyme source for subsequent esterase activity assays.

Protein concentration of enzyme preparations was determined with a commercially available bicinchoninic acid protein assay kit (Pierce Chemical) using bovine serum albumin as the standard.

Esterase Activity Assay. Esterase activity was determined by colorimetric measurement of $\beta$-naphthol formation from the substrate $\beta$-naphthyl acetate. In this study, the approach of Van Asperen (1962) was adapted to a 96-well microplate format. The assay mixture contained $188 \mu \mathrm{l}$ of $0.02 \mathrm{M}$ sodium phosphate buffer ( $\mathrm{pH} 7.0$ ), $2 \mu$ l of $25 \mathrm{mM}$ substrate diluted in acetone, and $10 \mu \mathrm{l}$ of enzyme preparation. Reagents were added to wells of a 96 -well flat bottom microplate (353912 Falcon, BD Biosciences Discovery Labware, Franklin Lakes, NJ) and incubated at $30^{\circ} \mathrm{C}$ for $15 \mathrm{~min}$ in a bio kinetics reader (Bio-Tek Instruments, Winooski, VT). The reaction was stopped by the addition of $33.2 \mu \mathrm{l}$ of $0.3 \%$ fast blue BN (tetrazotized $O$-dianisidine) in $3.5 \%$ sodium dodecyl sulfate. The color was allowed to develop for $15 \mathrm{~min}$ at ambient temperature, and the absorbance was recorded at $600 \mathrm{~nm}$ in the micoplate reader. Formation of product was determined from a standard curve of $\beta$-naphthol $(0-50 \mu \mathrm{M})$.

Nondenaturing Polyacrylamide Gel Electrophoresis (PAGE). Nondenaturing PAGE was carried out in a vertical electrophoresis unit (Mini Protean II, BioRad) using a $7.5 \%$ separating gel and $4 \%$ stacking gel with a continuous Tris-glycine running buffer system ( $50 \mathrm{mM}$, pH 8.3). Samples $(10 \mu \mathrm{l}$ ) of enzyme preparation were diluted $1: 1$ with $2 \times$ sample buffer $[20 \%$ sucrose (wt:vol), $0.1 \%$ bromphenol blue in $50 \mathrm{mM}$ Tris-glycine running buffer ( $\mathrm{pH} 8.3$ ) ] before loading. Gels were run at constant voltage $(120 \mathrm{~V})$ for $75 \mathrm{~min}$ at $4^{\circ} \mathrm{C}$. Esterase protein bands were visualized by incubating the gel in the developing buffer $[0.02 \mathrm{M}$ sodium phosphate buffer (pH 7.0), with $2 \%$ (vol:vol) $30 \mathrm{mM} \beta$-naphthyl acetate] at $30^{\circ} \mathrm{C}$ for $15 \mathrm{~min}$ before adding $0.04 \%$ (wt:vol) fast blue BN (tetrazotized $O$ dianisidine).

Optimal Conditions for Esterase Activity Assays. To investigate the effects of temperature on esterase activity, enzyme activity determinations were conducted from 20 to $60^{\circ} \mathrm{C}$ in $5^{\circ} \mathrm{C}$ increments. Incubation 

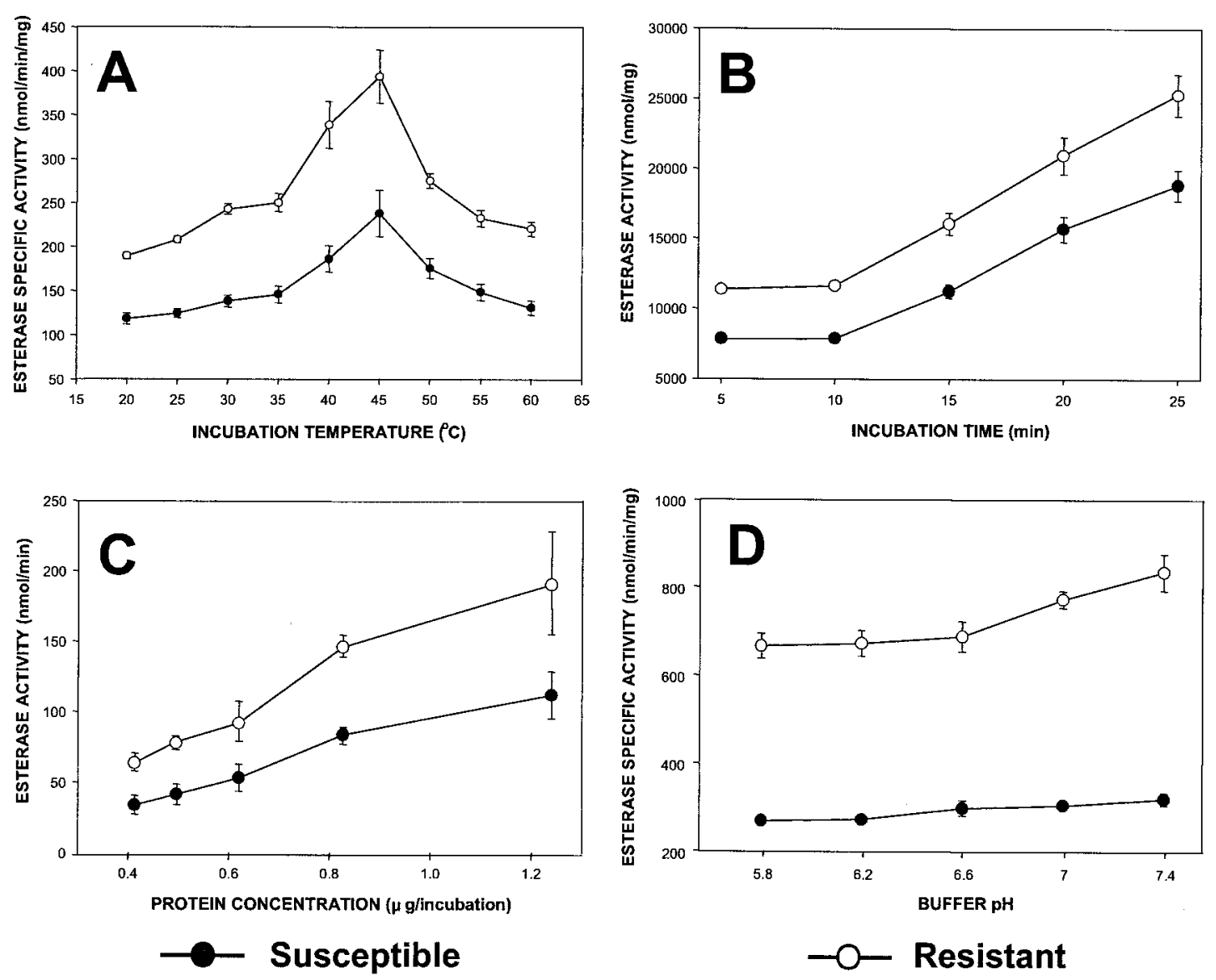

Fig. 1. Optimal conditions for D. v. virgifera esterase activity assay. (A) Esterase-specific activity as a function of incubation temperature. (B) Esterase activity as a function of incubation time. (C) Esterase activity as a function of protein concentration. (D) Esterase specific activity as a function of $\mathrm{pH}$. Each point represents the mean of at least nine determinations.

times were examined from 5 to 25 min in 5 -min increments. The effect of protein concentration was measured from 0.4 to $1.2 \mu \mathrm{g} /$ reaction. Sodium phosphate buffers from $\mathrm{pH}$ 5.8-7.4 were also tested.

To determine substrate specificity, the following naptholic esters differing in length of the carbon side chain were used: $\alpha$-naphthyl acetate (C-2), $\alpha$-naphthyl propionate (C-3), $\alpha$-naphthyl butyrate (C-4), $\alpha$-naphthyl valerate (C-5), $\alpha$-naphthyl caproate (C$6), \alpha$-naphthyl caprylate (C-8), $\alpha$-naphthyl myristate (C-14), $\beta$-naphthyl acetate (C-2), $\beta$-naphthyl butyrate (C-4), and $\beta$-naphthyl caprate (C-10).

Esterase Distribution. Developmental Stages. Homogenates of 50 first instars, 10 third instars, and 10 adult rootworms were prepared as described previously. General esterase activities and protein levels from each developmental stage were examined using esterase activity assays and nondenaturing PAGE, respectively.

Subcellular Distribution. Ten adult rootworms were homogenized in $1.0 \mathrm{ml}$ of ice-cold $0.1 \mathrm{M}$ sodium phosphate homogenate buffer ( $\mathrm{pH} 7.8$ ) without Tri- ton $\mathrm{X}-100$ as described previously. The homogenate was centrifuged at $10,000 \times g\left(4^{\circ} \mathrm{C}\right)$ for $20 \mathrm{~min}$. The resulting pellet corresponding to nuclei and mitochondria was resuspended in a separate $1.0-\mathrm{ml}$ aliquot of homogenization buffer. The $10,000 \times g$ supernatant was centrifuged in an Optima TLX-1M-1 ultracentrifuge (Beckman, Allendale, NJ) at 100,000 $\times g\left(4^{\circ} \mathrm{C}\right)$ for $1 \mathrm{~h}$. The resulting microsomal pellet representing membrane bound protein was resuspended in $0.5 \mathrm{ml}$ of ice-cold homogenization buffer. The $100,000 \times g$ supernatant corresponded to the cytosolic fraction. Both Protein concentration and esterase activity of crude homogenates as well as the three subcellular fractions from resistant and susceptible populations were examined.

Body Distribution. The distribution of general esterases in adult $D$. $v$. virgifera was determined by separately examining the head, thorax, and abdomen. Each body segment from 10 adults was homogenized as described previously. The $10,000 \times g$ supernatants from each segment were examined for both protein concentration and esterase activity. In all distribution 
experiments, three preparations were assayed from resistant and susceptible populations, with three determinations per preparation.

Single Insect Activity Assay. The abdomens of 48 beetles from each population were individually placed into the wells of a 96-well flat bottom microplate containing $100 \mu \mathrm{l}$ of ice-cold homogenization buffer. Abdomens were homogenized by a combination of vertical and circular movement with a 96-spoke multichannel homogenizer (MC96, Dan-Kar, Reading, MA) for $30 \mathrm{~s}$. The homogenate $(10 \mu \mathrm{l})$ from each beetle was then transferred to a new microplate with a multichannel pipette and diluted 100 -fold. The microplate was kept on ice for the subsequent activity assays. The same procedure described above was applied to third instars of the resistant York and Phelps county populations and the susceptible Saunders County population, except that the whole body was used for homogenization.

The frequency distributions of esterase activity were compared by fitting data to an expected frequency of a theoretical normal distribution around the same mean (Sokal and Rholf 1969). Significance of difference from a normal distribution was determined from the Shapiro-Wilk statistic, W (Shapiro and Wilk 1965). Two statistical parameters, skewness and kurtosis, describe the dispersion of esterase activities from a normal distribution. Negative and positive values of skewness indicate asymmetry to the left and right, respectively, whereas the negative and positive values of kurtosis imply lower and higher frequencies of observations near the mean and tails of the distributions, respectively.

The appropriate summary statistics were calculated using SAS PROC UNIVARIATE (SAS Institute 2001). The significance of differences in esterase activity among the eight populations was analyzed by one-way analysis of variance (ANOVA), and differences among esterase means were determined by a protected least significant difference (LSD) test (Neter et al. 1985).

\section{Results}

Optimal Conditions for Esterase Activity Assay. The optimal conditions for measuring general esterase activities among resistant and susceptible $D$. v. virgifera populations are reported in Fig. 1A-D. The resistant and susceptible populations exhibited a similar trend in esterase activity toward $\beta$-naphthyl acetate at different incubation temperatures; however, the activity was consistently elevated in the resistant population. Activities in both populations increased almost linearly from 20 to $35^{\circ} \mathrm{C}$ followed by a sharp decrease in activity from 35 to $45^{\circ} \mathrm{C}$ (Fig. 1A). Activity decreased drastically above $45^{\circ} \mathrm{C}$, indicating considerable instability of the enzyme at higher temperatures.

The rate of $\beta$-naphthol formation increased linearly from 10 to $25 \mathrm{~min}$ of incubation time (Fig. 1B). A similar relationship was observed between the protein concentration and product formation. The rate of hydrolysis of $\beta$-naphthyl acetate was linear with increasing protein from 0.4 to $1.2 \mu \mathrm{g}$ per incubation (Fig. 1C).
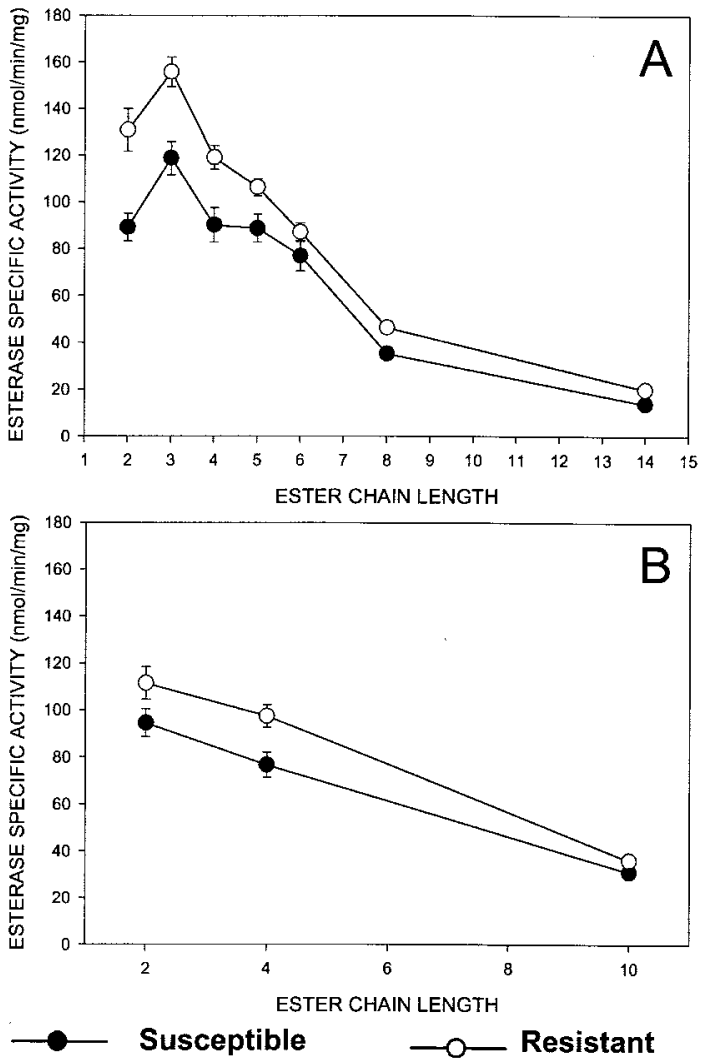

Fig. 2. Esterase activity toward naptholic esters differing in carbon side chain length. (A) $\alpha$-Naptholic esters (2, acetate; 3 , propionate; 4 , butyrate; 5 , valerate; 6 , caproate; 8 , caprylate; and 14, myristate. (B) $\beta$-Naptholic esters (2, acetate; 4 , butyrate; and 10 , caprate). Each point represents the mean of nine determinations.

A gradual increase in esterase activity was observed from $\mathrm{pH}$ 5.8-7.4 in both resistant and susceptible strains (Fig. 1D). At higher pH levels (>7.4), color formation after staining with $\beta$-naphthyl acetate was unstable (data not shown), and therefore, $\mathrm{pH} 7.0$ was chosen for routine measurement of esterase activity as described previously by Miota et al. (1998) and Wright et al. (2000).

Esterase activity toward naphtholic esters varying in length and position of the carbon side chain is shown in Fig. 2. Resistant and susceptible populations displayed similar patterns of esterase activity across all of the substrates tested. Both populations exhibited higher activity toward naphtholic esters with short alkyl side chains and a sharp decline in activity toward naphtholic esters with side chains greater than six carbon atoms in length. Although $D$. v. virgifera esterases were more active toward $\alpha$-naphthyl propionate (C-3) in both populations, $\alpha$-naphthyl acetate (C-2) consistently provided better discrimination between resistant and susceptible populations. However, virtually no differences were observed between $\alpha$ - and $\beta$-naphthyl acetate in discriminating resistant 
Table 1. Esterase activity toward $\alpha$ - and $\beta$-naphthyl acetate in different developmental stages from resistant and susceptible $D$. $v$. virgifera populations

\begin{tabular}{|c|c|c|c|c|c|c|c|c|c|c|}
\hline \multirow[t]{2}{*}{ Life stage } & \multicolumn{5}{|c|}{$\begin{array}{l}\text { Specific activity toward } \alpha \text {-naphthyl acetate } \\
(\mathrm{nmol} / \mathrm{min} / \mathrm{mg} ; \text { mean } \pm \mathrm{SEM})^{a}\end{array}$} & \multicolumn{5}{|c|}{$\begin{array}{l}\text { Specific activity toward } \beta \text {-naphthyl acetate } \\
(\mathrm{nmol} / \mathrm{min} / \mathrm{mg} ; \text { mean } \pm \mathrm{SEM})^{a}\end{array}$} \\
\hline & Saunders (S) & York $\left(\mathbf{R}_{1}\right)$ & $\mathrm{R}_{1} / \mathrm{S}^{b}$ & Phelps $\left(\mathrm{R}_{2}\right)$ & $\mathrm{R}_{2} / \mathrm{S}^{b}$ & Saunders (S) & York $\left(\mathrm{R}_{1}\right)$ & $\mathrm{R}_{1} / \mathrm{S}^{b}$ & Phelps $\left(\mathrm{R}_{2}\right)$ & $\mathrm{R}_{2} / \mathrm{S}^{b}$ \\
\hline 1st instar & $333.4 \pm 5.7$ & $700.5 \pm 4.5$ & 2.1 & $739.7 \pm 16.0$ & 2.2 & $304.7 \pm 3.5$ & $704.1 \pm 9.1$ & 2.3 & $619.3 \pm 7.1$ & 2.0 \\
\hline 3rd instar & $232.8 \pm 3.1$ & $871.9 \pm 20.5$ & 3.7 & $898.7 \pm 29.9$ & 3.9 & $242.9 \pm 5.2$ & $896.9 \pm 16.3$ & 3.7 & $957.2 \pm 19.2$ & 3.9 \\
\hline Adult & $455.4 \pm 2.6$ & $747.5 \pm 14.8$ & 1.6 & $634.7 \pm 14.0$ & 1.4 & $385.9 \pm 5.5$ & $678.9 \pm 14.7$ & 1.8 & $616.0 \pm 52.6$ & 1.6 \\
\hline
\end{tabular}

${ }^{a}$ Each value represents the mean of three different preparations with three determinations each $(n=9)$.

${ }^{b}$ Resistance ratios estimated by the specific activities of resistant (York, $\mathbf{R}_{1}$, and Phelps, $\mathbf{R}_{2}$ ) and susceptible (Saunders, $\mathrm{S}$ ) populations.

and susceptible populations either by esterase activity assay (Table 1) or nondenaturing PAGE (Fig. 3).

Esterase Distribution. Developmental Stages.Esterase activity toward both $\alpha$ - and $\beta$-naphthyl acetate in different developmental stages from resistant and susceptible D. v. virgifera populations are shown in Table 1. Activity was detected in all stages, although resistant populations consistently exhibited higher levels. Differences between the resistant and susceptible populations were more pronounced in third instars (3.9fold) relative to adults (1.5-fold) (Table 1$)$.

The esterase isozyme patterns in different developmental stages from both resistant and susceptible populations are shown in Fig. 3. Three esterase isozyme groups (I, II, and III) were visible across all
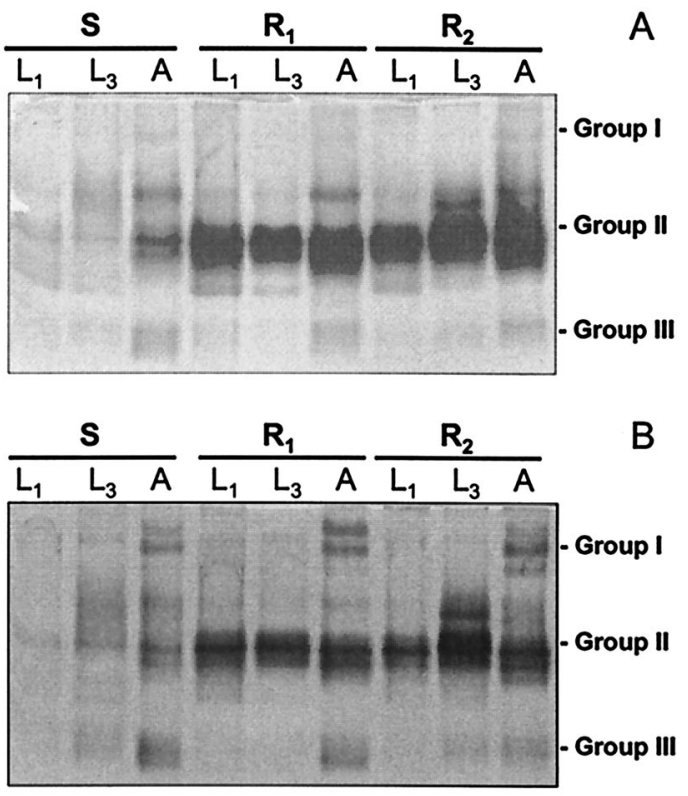

Fig. 3. Esterase isozyme patterns identified by nondenaturing PAGE using $\alpha$-naphthyl acetate (A) and $\beta$-naphthyl acetate (B) as substrate in different developmental stages of D. v. virgifera. Life stages selected from resistant York $\left(\mathrm{R}_{1}\right)$ and Phelps $\left(\mathrm{R}_{2}\right)$, and susceptible Saunders $(\mathrm{S})$ County populations were abbreviated as larval $(\mathrm{L})_{1}$, first instar; $\mathrm{L}_{3}$, third instar; and A, adult. Five micrograms of total protein extracted from each life stage was loaded into each well, and esterase isozymes were visually categorized into three groups (I, II, and III). the developmental stages, with group II esterases showing elevated activity in resistant populations.

Subcellular Distribution. General esterase activity was observed in all fractions (Table 2), especially in the mitochondria/nuclear $(10,000 \times g$ pellet $)$ and cytosolic $(100,000 \times g$ supernatant $)$ fractions. In both resistant and susceptible populations, cytosolic fractions exhibited the highest general esterase activity, although the distribution differed between resistant and susceptible populations. In resistant insects, general esterase activity was primarily localized in the cytosolic fraction, followed by the mitochondria/nuclear fraction and the microsomal fraction. In contrast, general esterase activity of the susceptible population was more evenly distributed among the cytosolic, mitochondrial and microsomal fractions. Cytosolic fractions had the highest specific activity level among all fractions from both resistant and susceptible populations, although resistant populations averaged $\approx 3.5$ fold higher activity.

Body Distribution. Esterase activity from three body segments of adult rootworms were distributed similarly between the resistant and susceptible populations, although the activity level in resistant populations exhibited significantly higher activity in both the thorax and abdomen but not the head (Fig. 4). The

Table 2. Subcellular distribution of general esterase activity from resistant and susceptible $D$. $v$. virgifera

\begin{tabular}{|c|c|c|c|}
\hline Population & Fraction & $\begin{array}{c}\text { Specific activity }^{a} \\
(\mathrm{nmol} / \mathrm{min} / \\
\mathrm{mg} \text { protein })\end{array}$ & $\begin{array}{l}\% \text { Total } \\
\text { activity }^{b}\end{array}$ \\
\hline \multirow[t]{5}{*}{ Saunders $(\mathrm{S})$} & Crude homogenate & $631.17 \pm 24.31$ & 100.00 \\
\hline & Mitochondria/nuclear & $593.77 \pm 60.06$ & 52.26 \\
\hline & Microsomal & $640.17 \pm 62.11$ & 28.17 \\
\hline & Cytosolic & $998.34 \pm 28.44$ & 64.15 \\
\hline & $\%$ Recovery & & 144.58 \\
\hline \multirow[t]{5}{*}{ York $\left(\mathrm{R}_{1}\right)$} & Crude homogenate & $1,342.37 \pm 58.14$ & 100.00 \\
\hline & Mitochondria/nuclear & $674.53 \pm 34.28$ & 27.92 \\
\hline & Microsomal & $665.77 \pm 34.83$ & 13.78 \\
\hline & Cytosolic & $3,612.29 \pm 165.24$ & 89.70 \\
\hline & $\%$ Recovery & & 131.39 \\
\hline \multirow[t]{5}{*}{ Phelps $\left(\mathrm{R}_{2}\right)$} & Crude homogenate & $2,549.75 \pm 174.52$ & 100.00 \\
\hline & Mitochondria/nuclear & $641.36 \pm 73.49$ & 15.72 \\
\hline & Microsomal & $815.67 \pm 21.18$ & 10.00 \\
\hline & Cytosolic & $3,363.96 \pm 247.92$ & 65.97 \\
\hline & $\%$ Recovery & & 91.68 \\
\hline
\end{tabular}

${ }^{a}$ Each value represents the mean of three preparations with three determinations each $(n=9)$.

${ }^{b}$ Percentage calculated based on activity of each fraction relative total activity in crude homogenate. 


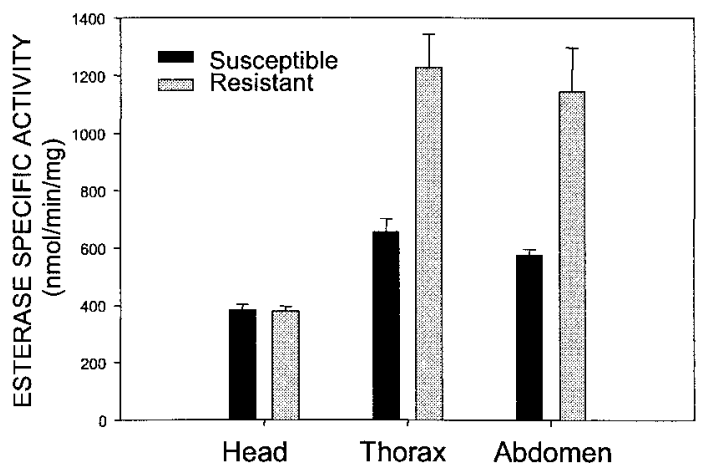

Fig. 4. Esterase activity distribution among different body segments of adult $D$. v. virgifera. The resistant and susceptible populations originated from Phelps and Saunders counties, Nebraska, respectively.

majority of esterase activity was located in the thorax and abdomen and the abdomen exhibited better discrimination between resistant and susceptible populations based on the nondenaturing PAGE (X.G.Z., unpublished data).

Individual Insect Activity Assays. Univariate analysis of esterase activity from individual beetles (Table 3 ) indicated that the mean esterase activities of resistant, intermediate, and susceptible populations were significantly different $(P<0.01)$. Intermediate and resistant populations had 1.9- and 2.6-fold higher activity, respectively, than that of the susceptible populations. However, there was considerable overlap among the frequency histograms for all eight $D$. $v$. virgifera field populations examined (Fig. 5). Esterase activity distributions differed significantly from a normal distribution $(P<0.05)$ and were statistically skewed to the right (positive skewness) in all populations tested except for the resistant Gresham population from York County (12.5\% bioassay mortality with a -0.09 skewness). Both positive kurtosis (a peaked distribution) and negative kurtosis (a flat distribution) were apparent among the eight field populations. The other resistant population from Phelps County (Nitchie: $7 \%$ bioassay mortality; kurtosis $=$ 2.42) displayed a relatively normal distribution.
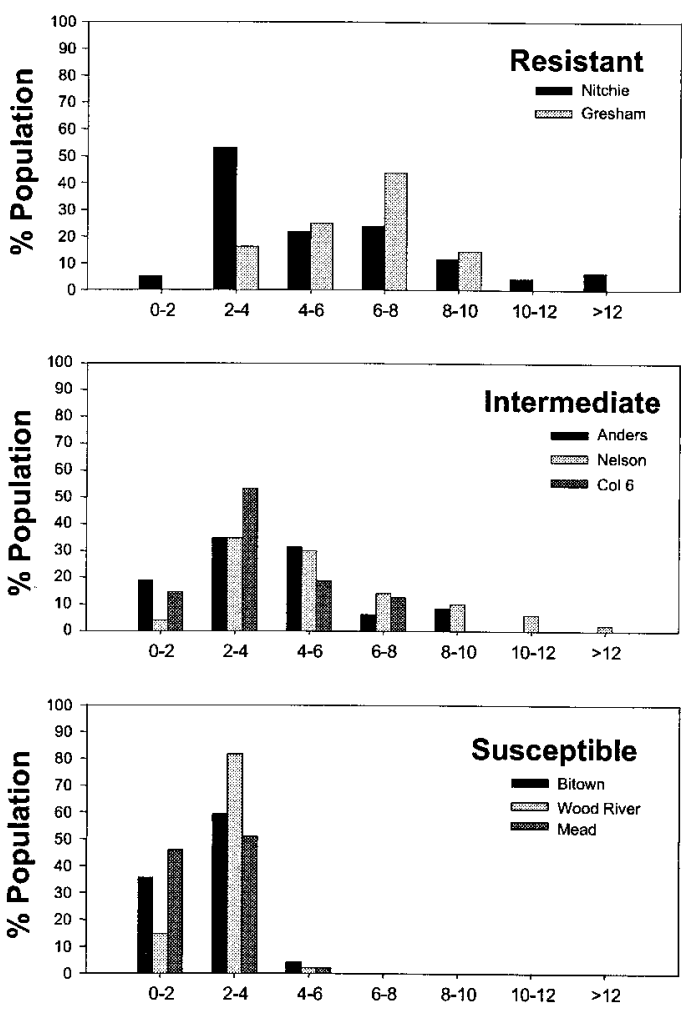

Esterase Activity Range (nmol/15min)

Fig. 5. Frequency distributions of esterase activities among resistant, intermediate, and susceptible $D$. v. virgifera populations based on the individual beetle assays.

Univariate analyses of esterase activity from individual larvae (Table 4) indicated that the mean esterase activities of resistant and susceptible populations were significantly different $(P<0.01)$. The resistant York and Phelps county populations (Gresham and Nitchie, respectively) were 7.3- and 5.8-fold, respectively, higher than that of the susceptible Saunders County populations (Mead). In addition, the frequency histograms of esterase activity (Fig. 6) clearly separated the resistant York and Phelps county pop-

Table 3. Univariate analyses of esterase activity of individual beetles from $D$. $v$. virgifera field populations

\begin{tabular}{|c|c|c|c|c|c|c|}
\hline \multirow{2}{*}{ Population } & \multirow{2}{*}{ Nebraska county } & \multirow{2}{*}{$\%$ Mortality $(\mathrm{SE})^{a}$} & \multicolumn{2}{|c|}{ Esterase activity $^{b}$} & \multirow{2}{*}{ Skewness } & \multirow{2}{*}{ Kurtosis } \\
\hline & & & Mean $\pm \mathrm{SE}^{c}$ & Median & & \\
\hline Mead & Saunders & $99.0(0.3)$ & $2.11(0.13) \mathrm{a}$ & 2.10 & 0.26 & -0.48 \\
\hline Wood River & Hall & $91.3(1.0)$ & $2.39(0.10) \mathrm{a}$ & 2.35 & 0.36 & -0.08 \\
\hline Bitown & Buffalo & $81.8(1.2)$ & $2.40(0.13) \mathrm{a}$ & 2.36 & 0.86 & 1.36 \\
\hline Anders & Gosper & $73.3(1.1)$ & $3.54(0.22) \mathrm{b}$ & 3.26 & 0.69 & -0.39 \\
\hline Nelson & Phelps & $49.5(1.7)$ & $3.96(0.30) \mathrm{b}$ & 3.66 & 0.79 & 0.26 \\
\hline X263 & Phelps & $29.6(1.5)$ & $5.24(0.43) \mathrm{c}$ & 4.46 & 1.10 & 0.40 \\
\hline Gresham & York & $12.5(1.1)$ & $5.94(0.24) \mathrm{c}$ & 6.08 & -0.09 & -0.62 \\
\hline Nitchie & Phelps & $7.0(1.0)$ & $5.97(0.49) \mathrm{c}$ & 5.50 & 1.31 & 2.42 \\
\hline
\end{tabular}

\footnotetext{
${ }^{a}$ Mortality at diagnostic concentration of methyl parathion $(1 \mu \mathrm{g} / \mathrm{ml}) ; n=100$ (Zhou et al. 2002).

${ }^{b}$ Nanomoles of $\alpha$-naphthol formed per individual insect per 15-min incubation.

${ }^{c}$ Means of esterase activity followed by the same letter are not significantly different (LSD test; $P>0.05$ ). At least 48 individual adults were assayed in each population.
} 
Table 4. Univariate analyses of esterase activity of individual larvae $\left(F_{1}\right.$ generation) from selected $D$. v. virgifera field populations

\begin{tabular}{lcccrrr}
\hline \hline \multirow{2}{*}{ Population } & \multirow{2}{*}{ Nebraska county } & \multirow{2}{*}{ Resistance Ratio $^{a}$} & \multicolumn{2}{c}{ Esterase activity $^{b}$} & \multirow{2}{*}{ Skewness } & \multirow{2}{*}{ Kurtosis } \\
\cline { 4 - 5 } & & & Mean $\pm \mathrm{SE}^{c}$ & Median & & \\
\hline Mead & Saunders & 1.0 & $2.50(0.42) \mathrm{a}$ & 1.94 & 3.50 & 12.86 \\
Gresham & York & $14.8^{d}$ & $18.35(0.91) \mathrm{b}$ & 19.25 & -1.11 & 0.60 \\
Nitchie & Phelps & $28.0^{e}$ & $14.48(1.27) \mathrm{c}$ & 13.36 & 0.04 & -0.41 \\
\hline
\end{tabular}

${ }^{a}$ Resistant ratios based on $\mathrm{LD}_{50}$ values that were obtained by topical bioassays toward methyl parathion.

${ }^{b}$ Nanomoles of $\alpha$-naphthol formed per individual insect per 15-min incubation.

${ }^{c}$ Means of esterase activity followed by the same letter are not significantly different $(P>0.05$; LSD test). At least 30 individual larvae were assayed in each population.

${ }^{d}$ Estimated by Wright et al. (1999).

${ }^{e}$ Estimated by Wright et al. (2000).

ulations from the susceptible Saunders County population. The esterase activity distribution in the susceptible Saunders County population was skewed to the right (positive skewness), and exhibited a typical peaked distribution (positive kurtosis). In contrast, the resistant York County population was skewed to the left (negative skewness), and had a rather flat distribution (kurtosis $=0.60$ ). The resistant Phelps County population exhibited a relatively normal and flat distribution ( skewness $=0.04$; negative kurtosis) .

\section{Discussion}

Although resistant and susceptible populations of $D$. v. virgifera displayed similar patterns of general esterase activities toward different model substrates and under different assay conditions, resistant populations consistently exhibited higher levels of activity relative to their susceptible counterpart. Similarities in properties and significantly greater activity support the involvement of quantitative rather than qualitative differences in isozyme composition between resistant and susceptible populations as the underlying resistance mechanism.

$D$. v. virgifera resistance-associated esterases were localized in the cytosolic fraction, were most abun-

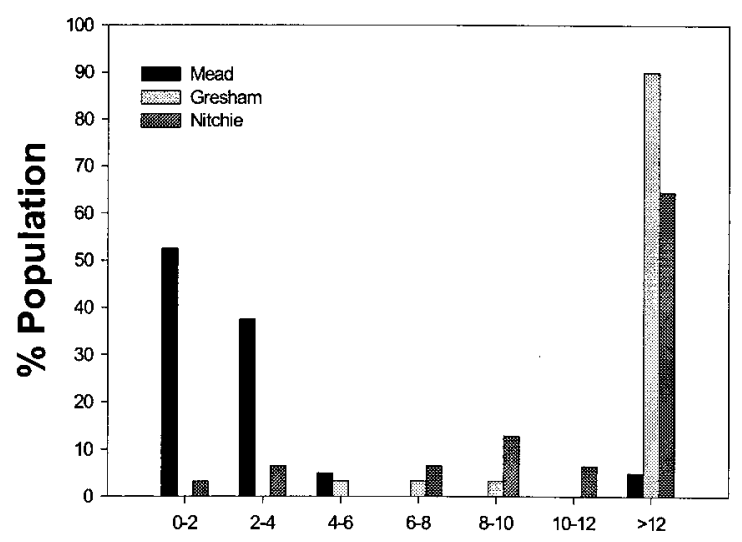

Esterase Activity Range (nmol/15min)

Fig. 6. Frequency distributions of esterase activities between resistant (A) and susceptible (B) D. v. virgifera populations based on individual larval assays. dant in thoracic and abdominal tissues, and were present in both larval and adult stages. Differences in intensity of specific esterase isozymes as displayed by nondenaturing PAGE seem to account for differences in total esterase activity among populations. The distinct differences in staining intensity of esterase isozymes in native PAGE between resistant and susceptible populations indicated the importance of the group II esterase isozymes in esterase-mediated resistance, and further suggest that quantitative differences in group II isozymes are at least partially responsible for resistance.

When comparing esterase activity between adults and third instars in resistant populations, larval preparations exhibited consistently higher activity than adults. This difference is consistent with previous results from topical bioassays with the same resistant populations, in which third instars averaged 1.5-fold higher methyl parathion resistance ratios relative to adults ( Meinke et al. 1998, Wright et al. 2000). Because both larvae and adults exhibited elevated esterase activities in resistant populations, it is apparent that selection of one life stage has the potential to impact resistance in another stage (i.e., selection of adults equates to selection of all life stages). However, the resistance seems to be relatively specific to methyl parathion because the field performance of other soil insecticides, including other organophosphates, does not seem to be significantly affected by resistance (Wright et al. 2000).

Examination of elevated esterase activity by simple activity assays has been commonly used to implicate the involvement of hydrolytic mechanisms in insecticide resistance (Soderlund and Bloomquist 1991). This technique allows both qualitative and quantitative measurement of enzyme activities from individual insects and can provide an estimate of resistance frequency in field populations (Rose et al. 1995). For the past $10 \mathrm{yr}$, there has been an increasing tendency to conduct simple activity assays using a 96-well microplate format. The microplate assays can simultaneously process and analyze a larger set of samples in a short time compared with traditional spectrophotometric assays (Dary et al. 1990). Based on individual D. v. virgifera activity assays, frequency histograms of general esterase activity were established. Unlike conventional bioassays that measure the average response of a heterogeneous population, biochemical monitor- 
ing approaches have the ability to detect subtle changes in resistant gene frequency caused by chemical selection (Devonshire 1989).

Although the mean activity of individual beetles was significantly different between resistant and susceptible populations, the assay apparently lacks diagnostic potential because of substantial overlap among populations. In contrast, single larva assays seemed to reliably distinguish resistant and susceptible populations, and therefore larval esterase activity assays may provide an alternative diagnostic method for resistance monitoring. Although organophosphate soil insecticides have thus far been fairly effective against rootworm larvae (Wright et al. 2000), the possibility of ineffective control still exists.

In a parallel study, native PAGE assays, an electrophoresis-based biochemical technique, provide a reliable biochemical marker (group II esterase isozymes) for detection of methyl-parathion resistance in individual beetles (Zhou et al. 2002).

General esterase activity assays, however, do have limitations and constraints. In our individual $D$. $v$. virgifera activity assays, the enzyme source consisted of crude homogenate that contained at least three groups and multiple esterase isoforms. Devonshire (1989) pointed out that some isoforms unrelated to resistance are able to metabolize a model substrate, and therefore can mask subtle differences in enzyme activity associated with resistance. The complexity of the multiple resistance mechanisms in $D$. v. virgifera (Miota et al. 1998; Scharf et al. 1999a, b, 2000a, b, 2001; Zhou et al. 2002) may ultimately limit the application of esterase activity assays in resistance monitoring (Denholm et al. 1990). Although biochemical monitoring tools such as esterase activity assays are by no means a universal alternative to conventional bioassay techniques, they can complement bioassays and provide information about the dynamics and evolution of resistance among field populations.

\section{Acknowledgments}

We thank ZB Mayo and David Taylor for valuable comments on an earlier draft of this manuscript. Jim Brown and Jenny Stebbing helped collect and maintain $D$. v. virgifera field populations. Support for this project was provided by DuPont, FMC, Zeneca, American Cyanamid, Dow Agrosciences, and USDA Specific Cooperative Agreement 585447-6-116. This is journal series paper 14058, NE Agricultural Research Division and contribution No. 1152 of the Department of Entomology, University of Nebraska.

\section{References Cited}

Ball, H. J., and G. T. Weekman. 1963. Insecticide resistance in the western corn rootworm in Nebraska. J. Econ. Entomol. 55: 439-441.

Comis, D. 1997. Corn Belt growers give areawide IPM a try. U.S. Dep. Agric.-Agric. Res. Serv. 45: 4-7.

Dary, O., G. P. Georghiou, E. Parsons, and N. Pasteur. 1990. Microplate adaptation of Gomori's assay for quantitative determination of general esterase activity in single insects. J. Econ. Entomol. 83: 2187-2192.
Denholm, I., K. J. Gorman, G. D. Moores, and A. L. Devonshire. 1990. Biochemical assays for insecticide resistance: strengths and limitations. Brighton Crop Prot. Conf. Pests Dis. 3: 1175-1180.

Devonshire, A. L. 1989. The role of electrophoresis in the biochemical detection of insecticide resistance, pp. 363374. In D. L. Hugh and J. D. Hollander (eds.), The Systematics Association special volume. Electrophoretic studies on agricultural pests, vol. 39 Oxford University Press, New York.

Hill, R. E., E. Hixson, and M. H. Muma. 1948. Corn rootworm control tests with benzene hexachloride, DDT, nitrogen fertilizers, and crop rotations. J. Econ. Entomol. 41: 392-401.

Jackson, J. J. 1986. Rearing and handling of Diabrotica virgifera and Diabrotica undecimpunctata howardi, pp. 2547. In J. L. Krysan and T. A. Miller (eds.), Methods for the study of pest Diabrotica. Springer, New York.

Levine, E., and H. Oloumi-Sadeghi. 1991. Management of diabroticite rootworms in corn. Annu. Rev. Entomol. 36: 229-255.

Meinke, L. J. 1995. Adult corn rootworm management. Univ. Neb. Agric. Res. Div. Misc. Publ. 63.

Meinke, L. J., B. D. Siegfried, R. J. Wright, and L. D. Chandler. 1997. Western corn rootworm resistance to insecticides: current situation in Nebraska. Proc. Ill. Agric. Pestic. Conf. 88-92.

Meinke, L. J., B. D. Siegfried, R. J. Wright, and L. D. Chandler. 1998. Adult susceptibility of Nebraska western corn rootworm (Coleoptera: Chrysomelidae) populations to selected insecticides. J. Econ. Entomol. 91: 594-600.

Metcalf, R. L. 1986. Foreword. In J. L. Krysan and T. A Smith (eds.), Methods for the study of pest Diabrotica. Springer, New York.

Miota, F., M. E. Scharf, M. Ono, P. Marcon, L. J. Meinke, R. J. Wright, L. D. Chandler, and B. D. Siegfried. 1998. Mechanisms of methyl and ethyl parathion resistance in the western corn rootworm (Coleoptera: Chrysomelidae). Pestic. Biochem. Physiol. 61: 39-52.

Neter, J., W. Wasserman and M. H. Kutner. 1985. Applied linear statistical models. R. D. Irwin, Homewood, IL.

Pike, D. R., K. L. Steffey, M. E. Gary, H. W. Kirby, D. I. Edwards, and R. H. Hornbaker. 1995. Biologic and economic assessment of pesticide use on corn and soybeans, National Agricultural Pesticide Impact Assessment Program Report No. 1-CA-95.

Rose, R. L., L. Barbhaiya, R. M. Roe, G. C. Rock, and E. Hodgson. 1995. Cytochrome P450-associated insecticide resistance and the development of biochemical diagnostic assays in Heliothis virescens. Pestic. Biochem. Physiol. 51: 178-191.

SAS Institute. 2001. SAS user's guide: Statistics, version 8.2 SAS Institute, Cary, NC.

Scharf, M. E., L. J. Meinke, B. D. Siegfried, R. J. Wright, and L. D. Chandler. 1999a. Carbaryl susceptibility, diagnostic concentration determination, and synergism for U.S. populations of western corn rootworm (Coleoptera: Chrysomelidae). J. Econ. Entomol. 92: 33-39.

Scharf, M. E., L. J. Meinke, R. J. Wright, L. D. Chandler, and B. D. Siegfried. 1999b. Metabolism of carbaryl by insecticide-resistant and -susceptible western corn rootworm populations (Coleoptera: Chrysomelidae). Pestic. Biochem. Physiol. 63: 85-96.

Scharf, M. E., B. D. Siegfried, L. J. Meinke, and L. D. Chandler. 2000a. Fipronil metabolism, oxidative sulfone formation and toxicity among organophosphate- and carbamate-resistant and susceptible western corn rootworm populations. Pest Manage. Sci. 56: 757-766. 
Scharf, M. E., B. D. Siegfried, L. J. Meinke, R. J. Wright, and L. D. Chandler. 2000b. Cytochrome P450-mediated Ndemethylation activity and induction in insecticide-resistant and susceptible western corn rootworm populations (Coleoptera: Chrysomelidae). Pestic. Biochem. Physiol. 67: 137-143.

Scharf, M. E., S. Parimi, L. J. Meinke, L. D. Chandler, and B. D. Siegfried. 2001. Expression and induction of three family 4 cytochrome P450 (CYP4)* genes identified from insecticide-resistant and susceptible western corn rootworms, Diabrotica virgifera virgifera. Insect Mol. Biol. 10: 139-146.

Shapiro, S. S., and M. B. Wilk. 1965. An analysis of variance test for normality. Biometrika 52: 591-611.

Soderlund, D. M., and J. R. Bloomquist. 1991. Molecular mechanisms of insecticide resistance, pp. 58-96. In R. T. Roush and B. E. Tabashnik [eds], Pesticide resistance in arthropods. Chapman and Hall, New York.

Sokal, R. R. and F. J. Rholf. 1969. Biometry. Freeman, San Francisco.
Spike, B. P., and J. J. Tollefson. 1991. Yield response of corn subjected to western corn rootworm (Coleoptera: Chrysomelidae) infestation and lodging. J. Econ. Entomol. 84: 1585-1590.

Van Asperen, K. 1962. A study of housefly esterases by means of a sensitive colorimetric method. J. Insect Physiol. 8: 401-416.

Wright, R. J., M. E. Scharf, L. J. Meinke, X. Zhou, B. D. Siegfried, and L. D. Chandler. 2000. Larval susceptibility of an insecticide-resistant western corn rootworm (Coleoptera: Chrysomelidae) population to soil insecticides: laboratory bioassays, assays of detoxification enzymes, and field performance. J. Econ. Entomol. 93: 7-13.

Zhou, X. G., M. E. Scharf, P. Srinivas, L. J. Meinke, R. J. Wright, L. D. Chandler, and B. D. Siegfried. 2002. Diagnostic assays based on esterase-mediated resistance mechanisms in western corn rootworms (Coleoptera: Chrysomelidae). J. Econ. Entomol. 95: 1261-1266.

Received for publication 2 May 2003; accepted 4 August 2003 